Ferrata Storti Foundation

\title{
Extensive multilineage analysis in patients with mixed chimerism after allogeneic transplantation for sickle cell disease: insight into hematopoiesis and engraftment thresholds for gene therapy
}

Haematologica 2020

Volume 105(5):1240-1247

\section{Correspondence: \\ ALESSANDRA MAGNANI \\ alessandra.magnani@aphp.fr \\ Received: May 24, 2019. \\ Accepted: September 18, 2019. \\ Pre-published: September 19, 2019.}

doi:10.3324/haematol.2019.227561

Check the online version for the most updated information on this article, online supplements, and information on authorship \& disclosures: www.haematologica.org/content/105/5/1240

(C)2020 Ferrata Storti Foundation

Material published in Haematologica is covered by copyright. All rights are reserved to the Ferrata Storti Foundation. Use of published material is allowed under the following terms and conditions:

https://creativecommons.org/licenses/by-nc/4.0/legalcode. Copies of published material are allowed for personal or internal use. Sharing published material for non-commercial purposes is subject to the following conditions:

https://creativecommons.org//icenses/by-nc/4.0/legalcode, sect. 3. Reproducing and sharing published material for commercial purposes is not allowed without permission in writing from the publisher.

\begin{abstract}
Alessandra Magnani, ${ }^{1,2}$ Corinne Pondarré,,${ }^{3,4}$ Naïm Bouazza, ${ }^{5}$ Jeremy Magalon, ${ }^{6}$ Annarita Miccio, ${ }^{7,8}$ Emmanuelle Six,,${ }^{8,9}$ Cecile Roudaut, ${ }^{1}$ Cécile Arnaud, ${ }^{3}$ Annie Kamdem, ${ }^{3}$ Fabien Touzot, ${ }^{10}$ Aurélie Gabrion, ${ }^{1}$ Elisa Magrin, ${ }^{1,2}$ Chloé Couzin, ${ }^{1}$ Mathieu Fusaro, ${ }^{11}$ Isabelle André, ${ }^{8,9}$ Jean-Paul Vernant, ${ }^{12}$ Eliane Gluckman, ${ }^{13}$ Françoise Bernaudin, ${ }^{3}$ Dominique Bories ${ }^{14 *}$ and Marina Cavazzana ${ }^{1,2,8,9 *}$
\end{abstract}

\begin{abstract}
${ }^{1}$ Department of Biotherapy, Necker-Enfants Malades University Hospital, Assistance Publique-Hôpitaux de Paris, Paris, France; ${ }^{2}$ Biotherapy Clinical Investigation Center, Groupe Hospitalier Universitaire Ouest, Assistance Publique-Hôpitaux de Paris, INSERM CIC 1416, Paris, France; ${ }^{3}$ Centre de référence de drépanocytose, $\mathrm{CHIC}$ Centre Hospitalier Intercommunal de Créteil, Créteil, France; ${ }^{4}$ Inserm U955, Paris XII University, Créteil, France; ${ }^{5}$ Université Paris Descartes, EA7323, Sorbonne Paris Cité, CIC-1419 Inserm, Cochin-Necker, Paris, France; ${ }^{6}$ Cell Therapy Unit, Hôpital de la Conception, AP-HM, INSERM CIC BT 1409, Marseille, France; 'Laboratory of Chromatin and gene regulation during development, Imagine Institute, Paris, France; ${ }^{8}$ Paris Descartes-Sorbonne Paris Cité University, Imagine Institute, Paris; ${ }^{9}$ Human Lymphohematopoiesis Laboratory, Inserm UMR 1163, Imagine Institute, University Paris Descartes Sorbonne Paris Cité, Paris, France; ${ }^{10}$ Department of Immunology-Allergy-Rheumatology, CHU Sainte-Justine, University of Montreal, Montreal, Quebec, Canada; ${ }^{11}$ Study Center for Primary Immunodeficiencies, Assistance Publique-Hôpitaux de Paris (AP-HP), Necker-Enfants Malades University Hospital, Paris, France; ${ }^{12} \mathrm{Hematology} \mathrm{Department,} \mathrm{Pitié-Salpêtrière} \mathrm{Hospital,} \mathrm{Paris,} \mathrm{France;}$ ${ }^{13}$ Monacord Hôpital Saint Louis Paris, Centre Scientifique de Monaco, Monaco and Eurocord, Hôpital Saint Louis, Université Paris Diderot, Paris, France and ${ }^{14}$ Hématologie Moléculaire, Hôpital Henri Mondor, Université Paris Est, Créteil, France
\end{abstract}

*These authors are co-senior authors

\section{ABSTRACT}

1though studies of mixed chimerism following hematopoietic stem A cell transplantation in patients with sickle cell disease (SCD) may provide insights into the engraftment needed to correct the disease and into immunological reconstitution, an extensive multilineage analysis is lacking. We analyzed chimerism simultaneously in peripheral erythroid and granulomonocytic precursors/progenitors, highly purified B and T lymphocytes, monocytes, granulocytes and red blood cells (RBC). Thirty-four patients with mixed chimerism and $\geq 12$ months of follow-up were included. A selective advantage of donor $\mathrm{RBC}$ and their progenitors/precursors led to full chimerism in mature RBC (despite partial engraftment of other lineages), and resulted in the clinical control of the disease. Six patients with donor chimerism $<50 \%$ had hemolysis (reticulocytosis) and higher $\mathrm{HbS}$ than their donor. Four of them had donor chimerism $<30 \%$, including a patient with AA donor (hemoglobin $>10 \mathrm{~g} / \mathrm{dL}$ ) and three with AS donors (hemoglobin $<10 \mathrm{~g} / \mathrm{dL}$ ). However, only one vaso-occlusive crisis occurred with $68.7 \%$ $\mathrm{HbS}$. Except in the patients with the lowest chimerism, the donor engraftment was lower for $T$ cells than for the other lineages. In a context of mixed chimerism after hematopoietic stem cell transplantation for SCD, myeloid (rather than T cell) engraftment was the key efficacy criterion. Results show that myeloid chimerism as low as $30 \%$ was sufficient to prevent a vasoocclusive crisis in transplants from an AA donor but not constantly from an AS donor. However, the correction of hemolysis requires higher donor chimerism levels (i.e. $\geq 50 \%$ ) in both $\mathrm{AA}$ and $\mathrm{AS}$ recipients. In the future, this group of patients may need a different therapeutic approach. 


\section{Introduction}

Sickle cell disease (SCD) is a severe, monogenic disease associated with high mortality and morbidity rates. ${ }^{1}$ Together with $\beta$-thalassemia, SCD constitutes the world's most prevalent inherited disorder., ${ }^{2,3}$ Allogeneic human leukocyte antigen (HLA)-matched hematopoietic stem cell transplantation (HSCT) is the only curative treatment. Non-transplanted patients with SCD have a significantly shortened life expectancy, and experience disease-related complications throughout their lives. ${ }^{4-6}$ With the aim of improving care for patients with SCD, non-myeloablative, reduced-intensity conditioning regimens and haploidentical transplants are now being investigated. ${ }^{7-13}$ Furthermore, recent advances in gene therapy offer new perspectives for the treatment of this serious disease. ${ }^{14,15}$ However, the curative level of engraftment by genetically modified cells has yet to be determined.

Following HSCT, SCD patients may develop mixed chimerism (MC), i.e. the co-existence of host- and donorderived cells, which can nevertheless result in the clinical control of the disease. ${ }^{16-21} \mathrm{MC}$ is favored by the increasing use of non-myeloablative reduced-intensity conditioning regimens ${ }^{9-11}$ and high doses of antithymocyte globulin. ${ }^{22}$ The minimum level of donor chimerism required to reverse the clinical symptoms of SCD is still subject to debate. ${ }^{21,23}$ Some literature data show that a donor white blood cell (WBC) percentage as low as $11 \%$ is enough to provide clinically adequate disease control ${ }^{20}$ probably because the healthy cells have a survival advantage over SCD erythroid cells. ${ }^{24}$ This advantage is also observed in beta-thalassemia. ${ }^{25,26}$ However, donor chimerism at different stages of hematopoietic differentiation/development has yet to be analyzed in detail in a large cohort of SCD patients. Furthermore, donor chimerism (typically quantified as the proportion of donor-derived total circulating WBC) might be a poor indicator of the clinical outcome in patients with MC.

We therefore decided to perform an extensive analysis of donor chimerism in different cell lineage populations among a cohort of SCD patients having a mixed chimerism defined in the present study as host cells $>0.05 \%$ after a full myeloablative conditioning regimen and then genoidentical HSCT. Our objective was to study the hematopoietic reconstitution after HSCT in SCD patients and determine the engraftment threshold for stable disease control. To this end, we performed a multilineage analysis of donor chimerism concomitantly in highly purified peripheral blood myeloid and lymphoid lineages, in erythroid and granulomonocytic progenitors/precursors, and mature RBC in a large cohort of SCD patients with MC at last follow up.

Our present results may have implications not only for allogeneic HSCT but also for gene therapy trials based on the autologous transplantation of genetically modified CD34 $4^{+}$cells.

\section{Methods}

Between May 1990 and December 2013, 119 patients with SCD (registered at the Paris region's Pediatric Reference Center for SCD (Créteil, France)) underwent HLA-matched allogeneic HSCT at various transplantation centers. These patients are part of the French cohort previously published. ${ }^{4,22}$ Patients with symp- tomatic SCD (genotype: S/S or S/ 0) and an HLA-identical sibling donor (hemoglobin $[\mathrm{Hb}]$ genotype: AA, AS, A/ 0 or A/D-Punjab) underwent HSCT. The myeloablative conditioning regimen consisted of busulfan, cyclophosphamide (total dose: $200 \mathrm{mg} / \mathrm{kg}$ ), and rabbit anti-thymocyte globulin (total dose: $20 \mathrm{mg} / \mathrm{kg}$ ). The total dose of intravenous busulfan was adjusted to the recipient's body weight: $12.8 \mathrm{mg} / \mathrm{kg}$ for $>34 \mathrm{~kg}, 15.2 \mathrm{mg} / \mathrm{kg}$ for $23-34 \mathrm{~kg}, 17.6$ $\mathrm{mg} / \mathrm{kg}$ for $16-23 \mathrm{~kg}$, and $19.2 \mathrm{mg} / \mathrm{kg}$ for $9-16 \mathrm{~kg}$.

The main inclusion criteria for the present study were the development of $\mathrm{MC}$ for total WBC, at least 12 months of followup, and regular monitoring at the Reference Center. Post-HSCT blood samples were collected as part of routine care at last follow up. The patients' medical records were analyzed retrospectively.

\section{Sorting of hematopoietic subpopulations}

Cells were stained with specific, directly labeled monoclonal antibodies, according to the manufacturer's instructions. Chimerism was analyzed only when the population purity was $\geq 90 \%$.

\section{Clonogenic assay and DNA extraction}

Erythroid burst-forming-units (BFU-E) and granulocytemacrophage colony-forming-units (CFU-GM) progenitors/precursors were grown in semisolid methylcellulose medium with or without supplemented erythropoietin.

\section{Hemoglobin fraction analysis}

Values for $\mathrm{Hb}$ fractions $\mathrm{HbS}, \mathrm{HbF}$, and $\mathrm{HbA}$ were determined by cation-exchange high-performance liquid chromatography (HPLC).

\section{Chimerism analysis in mature lymphoid and myeloid populations and in progenitors/precursors}

Chimerism was determined in sorted, mature myeloid and lymphoid populations and concomitantly in BFU-E and CFUGM. Analysis was performed in the Molecular Hematology Laboratory at Henri Mondor Hospital (Creteil, France). Chimerism was first analyzed using quantitative real-time PCR assays for indel genomic polymorphisms (KimerDx kit, GenDX, Netherlands), using a method adapted from a previous publication $^{27}$ and by PCR-STR when the level was above $10 \%$. Mixed chimerism was defined as a recipient cell percentage above $0.05 \%$. Patients were divided into three groups according to the level of donor chimerism. The $70 \%$ and $95 \%$ cutoffs were chosen on the basis of published data ${ }^{22}$ and according to the limit usually employed in clinics, respectively. The donor chimerism in peripheral mature $\mathrm{RBC}$ was obtained by calculating the postHSCT proportion of donor HbA.

\section{Statistical analyses}

Statistical analysis was performed with ad hoc routines implemented in $\mathrm{R}$ software (http://www.R-project.org). The data are presented as proportions for categorical data and as median, interquartile range and range for quantitative data. Quantitative variables were compared with the non-parametric Wilcoxon tests and proportions with the Fisher's exact tests or the chisquared tests, as appropriate. Correlations between continuous variables were calculated using the non-parametric Spearman's rank correlation test. Wilcoxon signed-rank test for paired data was used to compare donor chimerism levels in $\mathrm{RBC}$ relative to BFU-E, CFU-GM and CD15 cells. A P-value of 0.05 was considered statistically significant for all analyses. Two-sided tests were used in all analyses. Please see the Online Supplementary Materials and Methods for a more detailed description of the methods used. 


\section{Results}

The study population and clinical outcomes

A total of 34 patients with MC and more than 12 months of follow-up at the Pediatric Reference Center were included in the study and then divided into three groups, according to the level of total WBC donor chimerism at last follow-up: $<70 \%$ (group 1, $\mathrm{n}=10$ ), 70 $95 \%$ (group 2, $n=14$ ), and $95-99.95 \%$ (group $3, n=10$ ). Six of the patients in group 1 had a donor chimerism level below 50\% (Table 1 and Online Supplementary Table S1).

In the study population as a whole, the median (range) age at transplant was 7.2 years (3.4-14.2); the median age did not differ significantly when comparing the three groups (8.1, 7 and 7.1 years in groups 1,2 and 3 , respectively; $P=0.8)$. The median duration of post-HSCT followup was 54.5 months (12-155); no significant differences were observed when comparing the three groups $(58.5,56$ and 42 months in groups 1,2 and 3 , respectively; $P=0.67$ ). The donor genotypes were as follows: $n=13$ for $A A, n=19$ for $\mathrm{AS}, \mathrm{n}=1$ for $\mathrm{A} / \mathrm{\beta} 0$, and $\mathrm{n}=1$ for $\mathrm{A} / \mathrm{D}-\mathrm{Punjab}$ donor. The proportion of AS donors was similar in the three groups $(50 \%$ in groups 1 and 2 , and $70 \%$ in group 3$)$. Examples of MC following HSCT with an AA or AS donor are shown

Table 1. Characteristics of the study population, and donor chimerism in cell subsets and progenitors/precursors.

\begin{tabular}{|c|c|c|c|c|c|c|}
\hline Variable & Level & Total $(n=34)$ & Group 1 (n=10) & Group 2 (n=14) & Group $3(n=10)$ & $P$ \\
\hline Age at HSCT (years) & median [iqr] (range) & $\begin{array}{c}7.2[5.8,9.1] \\
(3.4,14.2)\end{array}$ & $\begin{array}{c}8.1[6.0,10.5] \\
\quad(3.4,12.5)\end{array}$ & $\begin{array}{c}7.0[6.0,8.6] \\
(4.1,12.5)\end{array}$ & $\begin{array}{c}7.1[5.0,9.1] \\
(4.1,14.2)\end{array}$ & 0.80 \\
\hline $\begin{array}{l}\text { Follow-up after HSCT } \\
\text { (months) }\end{array}$ & median [iqr] (range) & $\begin{array}{c}54.5[37.2,81.8] \\
(12.0,155.0)\end{array}$ & $\begin{array}{c}58.5[37.0,122.5] \\
(21.0,155.0)\end{array}$ & $\begin{array}{c}56.0[46.8,76.2] \\
(12.0,91.0)\end{array}$ & $\begin{array}{c}42.0[36.2,92.5] \\
(12.0,127.0)\end{array}$ & 0.67 \\
\hline Donor Hb genotype & $\begin{array}{c}\mathrm{AA}, \mathrm{A} / \boldsymbol{\beta}^{0} \text { or A/D-Punjab } \\
\text { AS }\end{array}$ & $\begin{array}{l}15(44.1 \%) \\
19(55.9 \%)\end{array}$ & $\begin{array}{l}5(50.0 \%) \\
5(50.0 \%)\end{array}$ & $\begin{array}{l}7(50.0 \%) \\
7(50.0 \%)\end{array}$ & $\begin{array}{l}3(30.0 \%) \\
7(70.0 \%)\end{array}$ & 0.69 \\
\hline Donor HbS (\%) & median [iqr] (range) & $\begin{array}{c}32.0[0.0,37.5] \\
(0.0,44.6)\end{array}$ & $\begin{array}{c}16.6[0.0,38.5] \\
(0.0,44.6)\end{array}$ & $\begin{array}{c}15.8[0.0,35.7] \\
(0.0,39.8)\end{array}$ & $\begin{array}{c}33.6[7.9,37.7] \\
(0.0,38.7)\end{array}$ & 0.62 \\
\hline Donor HbA (\%) & median [iqr] (range) & $\begin{array}{c}53.0[51.7,54.7] \\
(46.9,57.4)\end{array}$ & $\begin{array}{c}54.0[52.8,55.4] \\
(51.7,57.4)\end{array}$ & $\begin{array}{c}52.7[49.2,53.8] \\
\quad(47.9,54.8)\end{array}$ & $\begin{array}{c}53.3[52.2,55.2] \\
(46.9,57.3)\end{array}$ & 0.46 \\
\hline $\begin{array}{l}\text { Hb level at last follow-up } \\
(\mathrm{g} / \mathrm{dL})\end{array}$ & median [iqr] (range) & $\begin{array}{c}12.9[11.5,13.4] \\
(8.4,14.4)\end{array}$ & $\begin{array}{c}10.8[9.9,13.1] \\
(8.4,14.2)\end{array}$ & $\begin{array}{c}13.1[12.8,13.3] \\
(9.6,14.4)\end{array}$ & $\begin{array}{c}12.9[11.9,13.5] \\
(10.9,13.7)\end{array}$ & 0.19 \\
\hline $\begin{array}{l}\text { Reticulocytes at last } \\
\text { follow-up (G/L) }\end{array}$ & median [iqr] (range) & $\begin{array}{c}36.0[30.0,57.3] \\
\quad(16.5,407.0)\end{array}$ & $\begin{array}{c}135.0[38.6,209.5] \\
\quad(31.2,407.0)\end{array}$ & $\begin{array}{c}36.4[27.8,55.8] \\
\quad(16.5,161.0)\end{array}$ & $\begin{array}{c}30.0[24.8,34.5] \\
(20.6,55.0)\end{array}$ & 0.0037 \\
\hline $\mathrm{HbA}(\%)$ & median [iqr] (range) & $\begin{array}{c}53.8[49.2,82.3] \\
(24.0,87.5)\end{array}$ & $\begin{array}{c}66.2[45.1,79.8] \\
(24.0,84.5)\end{array}$ & $\begin{array}{c}53.8[49.0,85.9] \\
(44.0,87.5)\end{array}$ & $\begin{array}{c}53.0[50.1,73.1] \\
(48.8,84.0)\end{array}$ & 0.71 \\
\hline $\mathrm{HbS}(\%)$ & median [iqr] (range) & $\begin{array}{c}33.0[0.0,38.1] \\
(0.0,68.1)\end{array}$ & $\begin{array}{c}20.6[4.6,45.1] \\
(0.0,68.1)\end{array}$ & $\begin{array}{c}16.4[0.0,37.2] \\
(0.0,41.2)\end{array}$ & $\begin{array}{c}33.7[8.1,39.1] \\
\quad(0.0,40.3)\end{array}$ & 0.46 \\
\hline $\mathrm{HbF}(\%)$ & median [iqr] (range) & $\begin{array}{c}1.0[0.0,1.9] \\
(0.0,6.5)\end{array}$ & $\begin{array}{c}1.2[0.2,1.8] \\
(0.0,4.4)\end{array}$ & $\begin{array}{c}1.0[1.0,2.6] \\
(0.0,6.5)\end{array}$ & $\begin{array}{c}1.1[0.0,1.7] \\
(0.0,5.5)\end{array}$ & 0.87 \\
\hline \multicolumn{7}{|l|}{ Chimerism analysis } \\
\hline Whole blood (\%) & median [iqr] (range) & $\begin{array}{c}89.3[60.0,95.7] \\
(16.0,99.8)\end{array}$ & $\begin{array}{c}37.0[19.5,56.0] \\
(16.0,66.0)\end{array}$ & $\begin{array}{c}89.3[85.3,91.9] \\
(72.0,93.4)\end{array}$ & $\begin{array}{c}97.2[96.3,98.8] \\
(95.7,99.8)\end{array}$ & $<0,0001$ \\
\hline $\mathrm{CD}^{+}(\%)$ & median [iqr] (range) & $\begin{array}{c}73.5[58.8,91.8] \\
(12.0,99.9)\end{array}$ & $\begin{array}{c}41.8[31.8,45.5] \\
(12.0,70.0)\end{array}$ & $\begin{array}{c}73.5[70.5,77.2] \\
(63.0,88.5)\end{array}$ & $\begin{array}{c}93.8[92.6,97.4] \\
(89.0,99.9)\end{array}$ & $<0,0001$ \\
\hline $\mathrm{CD} 19^{+}(\%)$ & median [iqr] (range) & $\begin{array}{c}94.0[56.0,97.8] \\
(11.0,99.9)\end{array}$ & $\begin{array}{c}36.5[15.5,49.8] \\
(11.0,90.0)\end{array}$ & $\begin{array}{c}95.2[88.2,97.8] \\
(73.0,98.7)\end{array}$ & $\begin{array}{c}98.6[96.9,99.4] \\
(93.5,99.9)\end{array}$ & $<0,0001$ \\
\hline $\mathrm{CD}_{14}{ }^{+}(\%)$ & median [iqr] (range) & $\begin{array}{c}96.5[52.5,99.6] \\
(9.4,100.0)\end{array}$ & $\begin{array}{c}33.5[18.5,56.8] \\
(9.4,98.5)\end{array}$ & $\begin{array}{c}96.4[94.6,98.5] \\
(72.0,99.9)\end{array}$ & $\begin{array}{c}99.7[99.5,99.9] \\
(98.2,100.0)\end{array}$ & 0.00013 \\
\hline $\mathrm{CD} 15^{+}(\%)$ & median [iqr] (range) & $\begin{array}{c}95.0[64.0,99.5] \\
(5.4,100.0)\end{array}$ & $\begin{array}{c}24.5[14.5,51.2] \\
(5.4,95.0)\end{array}$ & $\begin{array}{c}96.2[92.5,97.8] \\
(63.0,99.9)\end{array}$ & $\begin{array}{c}99.8[99.7,100.0] \\
\quad(95.1,100.0)\end{array}$ & 0.00022 \\
\hline BFU-E (\%) & median [iqr] (range) & $\begin{array}{c}97.7[65.5,99.9] \\
(0.0,100.0)\end{array}$ & $\begin{array}{c}39.0[31.0,61.0] \\
(0.0,76.0)\end{array}$ & $\begin{array}{c}98.1[94.5,99.1] \\
(52.0,99.9)\end{array}$ & $\begin{array}{c}99.9[99.9,99.9] \\
(97.2,100.0)\end{array}$ & $<0,0001$ \\
\hline CFU-GM (\%) & median [iqr] (range) & $\begin{array}{c}98.0[64.0,99.4] \\
(8.0,99.9)\end{array}$ & $\begin{array}{c}38.5[14.5,46.5] \\
(8.0,60.0)\end{array}$ & $\begin{array}{c}98.2[89.8,99.2] \\
(76.0,99.9)\end{array}$ & $\begin{array}{c}99.4[99.1,99.8] \\
(80.0,99.9)\end{array}$ & $<0,0001$ \\
\hline RBC (\%) & median [iqr] (range) & $\begin{array}{c}87.5[82.7,97.2] \\
(46.4,104.1)\end{array}$ & $\begin{array}{c}81.6[79.7,84.5] \\
(46.4,98.7)\end{array}$ & $\begin{array}{c}89.7[86.1,97.0] \\
(47.9,101.5)\end{array}$ & $\begin{array}{c}94.1[84.9,99.2] \\
(79.0,104.1)\end{array}$ & 0.039 \\
\hline
\end{tabular}
cells. 
in the Online Supplementary Figure S1.

Hemoglobin levels (overall median [range] concentration: $12.9 \mathrm{~g} / \mathrm{dL}$ [8.4-14.4]) were generally stable and clinically satisfactory. Median $\mathrm{Hb}$ level was lower in group 1 $(10.8 \mathrm{~g} / \mathrm{dL})$ than in group $2(13.1 \mathrm{~g} / \mathrm{dL})$ or group $3(12.9$ $\mathrm{g} / \mathrm{dL}$ ), although the difference was not statistically significant $(P=0.18)$. There was no difference in the mean $\mathrm{Hb}$ level between the set of patients with an AS donor (median [range] $12.8 \mathrm{~g} / \mathrm{dL}$ [8.4-14.3]) and the set with a non-AS donor (median [range] 13.1 g/dL [9.6-14.4]) $(P=0.61)$. A reticulocyte count at last follow-up greater than $100 \times 10^{9} / \mathrm{L}$ was observed in patients with WBC donor chimerism $<50 \%$. However, this was associated with $\mathrm{Hb}$ levels $<10$ $\mathrm{g} / \mathrm{dL}$ solely in patients with AS donor (see below).

The HbS fractions in patients after HSCT were similar to those of the donors, with the exception of the six patients with donor chimerism $<50 \%$ (see below). With the exception of patient \#2 (who experienced a single vasoocclusive crisis (VOC) with confirmed liver involvement; see below), no VOC were observed after transplantation.

\section{Donor chimerism in mature myeloid and lymphoid cells, and in granulomonocytic progenitors}

The chimerism profiles of mature lymphoid/myeloid lineages and of progenitors/precursors often differed from those recorded for total WBC (Table 1 and Online Supplementary Table S1). The levels of donor chimerism were correlated for $\mathrm{CD} 15^{+}$versus $\mathrm{CD} 14^{+}$cells (rho $=0.93$, $P=0.002), \mathrm{CD}_{1} 5^{+}$versus $\mathrm{CD} 19^{+}$cells (rho $=0.66, P=0.076$ ), and $\mathrm{CD} 14^{+}$versus $\mathrm{CD} 19^{+}$cells (rho $=0.69, P=0.028$ ) but not for $\mathrm{CD}_{15}{ }^{+}$versus $\mathrm{CD}^{+}$cells (rho $=-0.14, P=0.752$ ), $\mathrm{CD} 14^{+}$ versus $\mathrm{CD}^{+}$cells (rho $=-0.18, P=0.632$ ) or $\mathrm{CD}^{2} 9^{+}$versus $\mathrm{CD}^{+}$cells (rho $=0.44, P=0.199$ ) (Figure 1). The donor chimerism in CFU-GM correlated with that in $\mathrm{CD} 15^{+}$cells (rho $=0.8, P<0.001)$ (Online Supplementary Figure S2). We limited our correlation analyses to group 1 , in order to avoid bias due to the higher overall levels of donor chimerism in groups 2 and 3. Our analysis of chimerism in mature blood lineages showed that $\mathrm{T}$-cell chimerism was independent of the other lineages.

\section{The selective advantage of donor erythroid cells}

In order to investigate the donor chimerism in peripheral RBC in patients with $\mathrm{MC}$, we compared $\mathrm{HbS}$ fractions in patients after HSCT and in their donors. Overall, there was an excellent correlation between the HbS fraction in patients after HSCT and the fraction in the donors (rho $=0.94, P<0.001$ ) (Figure 2). The intra-class correlation coefficient ( $95 \%$ confidence interval [CI]) between these two variables was estimated to be $0.95(0.81-0.99)$. In all the patients other than the six with $\mathrm{MC}<50 \%$ (see below), $\mathrm{HbS}$ levels were similar to those observed in the donors.

In order to investigate this putative selective advantage over the course of erythroid development, we compared donor chimerism among mature RBC, BFU-E, CFU-GM and $\mathrm{CD} 15^{+}$cells (Figure 3 ). The $\mathrm{CD} 15^{+}$cell population was chosen as a benchmark for bone marrow engraftment because it lacks a selective advantage, is short-lived, and is thus unlikely to accumulate over time. As expected, there were no differences in myeloid lineage donor chimerism between $\mathrm{CD}_{15}{ }^{+}$cells and CFU-GM $(P=0.313)$. Inversely we observed a progressive enrichment in cells of donor origin during the development of the erythroid lineage in the periphery, with higher levels of donor chimerism in peripheral RBC versus CFU-GM and in BFU-E versus CFUGM $(P=0.016$ and $P=0.03$, respectively). A median (IOR) 2.0-fold (1.4-2.5) increase between donor chimerism in peripheral RBC versus BFU-E was observed, whereas, a 1.5-fold (1.2-2.2) increase was observed between BFU-E and CFU-GM.

Taken as a whole, these results evidenced a lineage-specific, selective advantage in donor erythroid cells. Full donor chimerism was achieved in peripheral RBC, independently of the level in other lineages. Interestingly, this
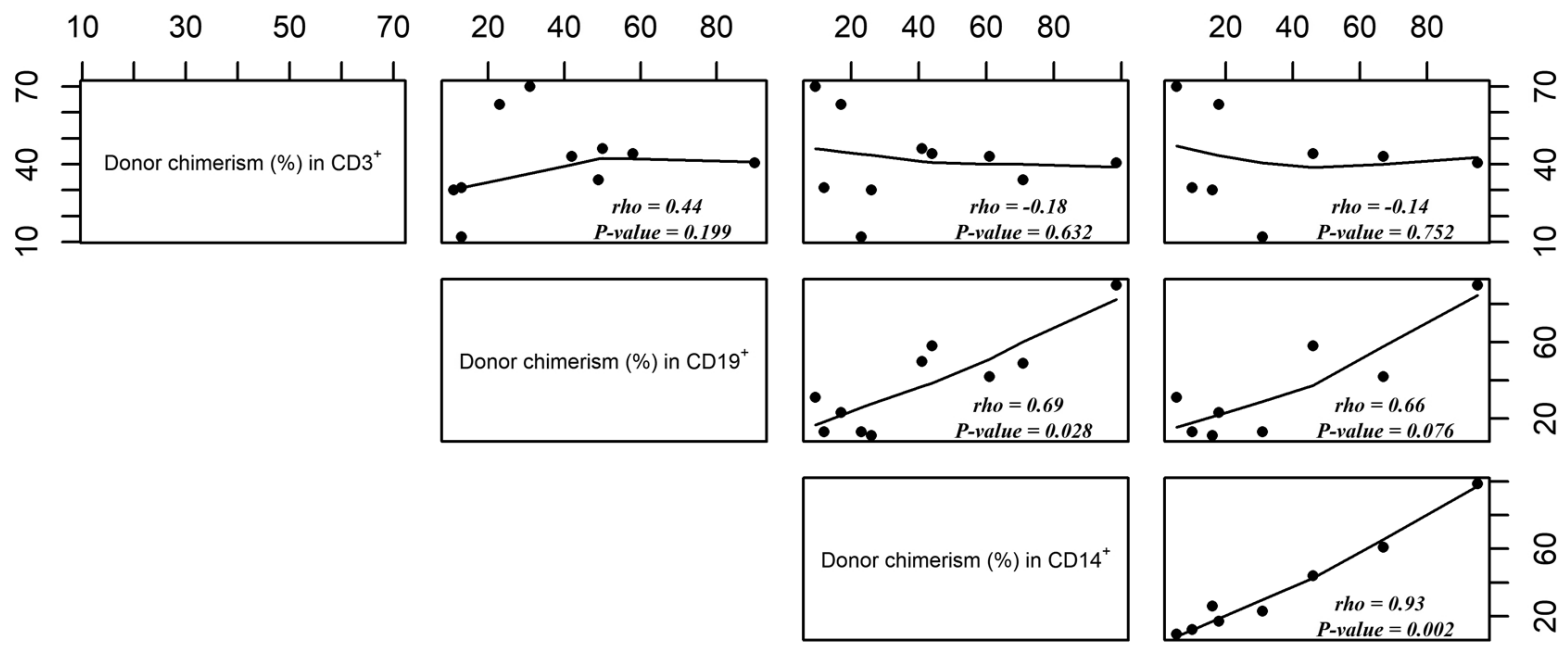

Figure 1. Correlation of donor chimerism levels (\%) in $\mathrm{CD}_{15} 5^{+}$versus $\mathrm{CD} 14^{+}$versus $\mathrm{CD} 19^{+}$versus $\mathrm{CD} 3^{+}$cells in sickle cell disease (SCD) patients with total white blood cell (WBC) chimerism $<70 \%$ (patients from group 1). Rho: Spearman's rank correlation coefficient.

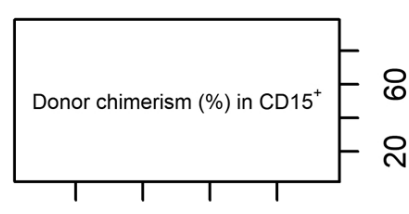

$20 \quad 40 \quad 60 \quad 80$ 


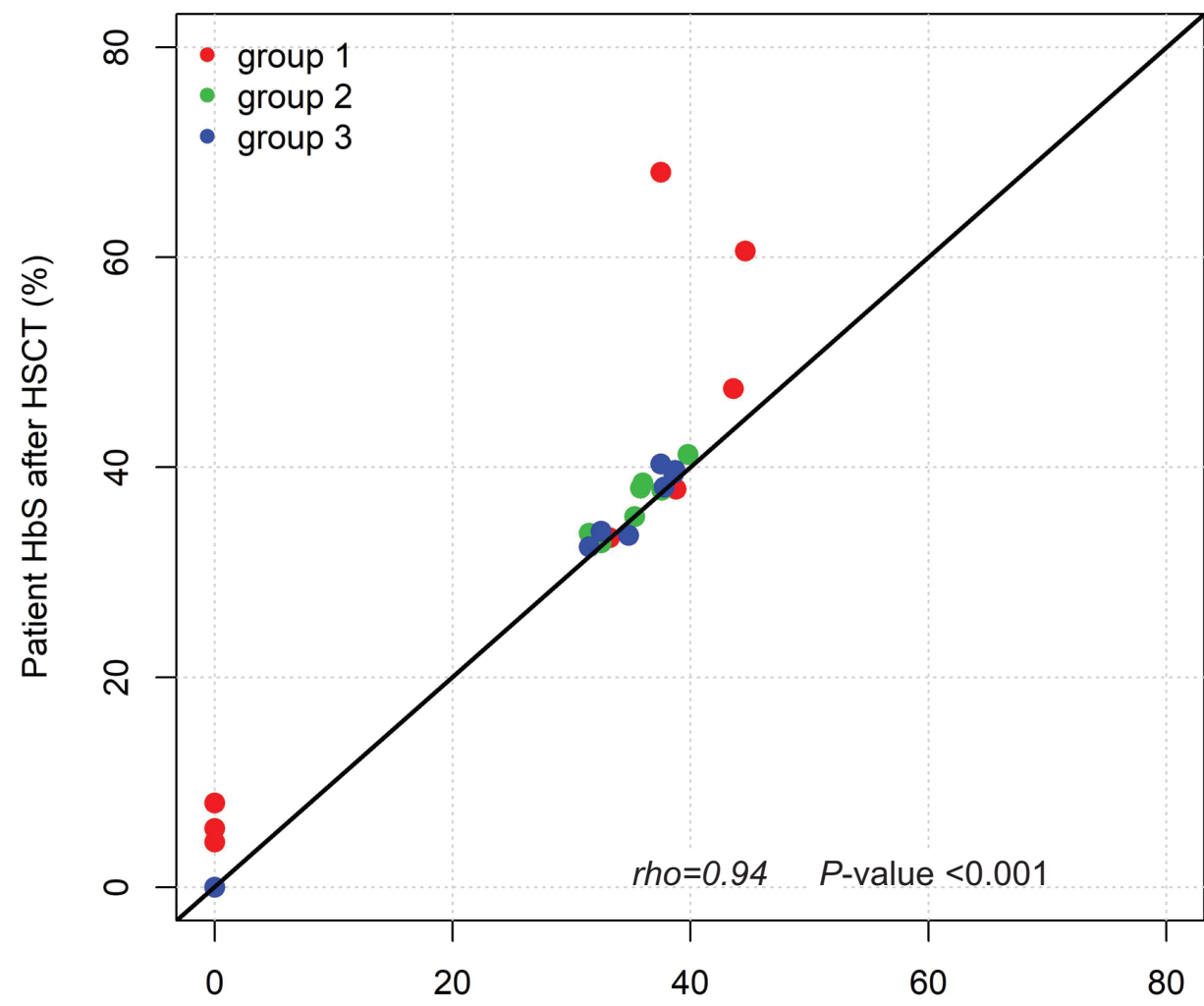

Figure 2. Correlation between $\mathrm{HbS}$ in patients after hematopoietic stem cell transplantation (HSCT) and in donors, regardless of the donor's genotype, divided into group 1 (mixed chimerism $[\mathrm{MC}]<70 \%$, red dots), group 2 (MC 70-95\%, green dots) and group 3 (MC 95-99.5\%, blue dots). The line corresponds to $y=x$. Rho: Spearman's rank correlation coefficient.

Donor $\mathrm{HbS}(\%)$

selective advantage was observed not only in the peripheral compartment but also in erythroid progenitors/precursors.

\section{Patients with WBC donor chimerism $\leq \mathbf{5 0} \%$}

Six patients in group 1 (three with AA donors and three with AS donors) presented with a total WBC donor chimerism level $\leq 50 \%$ (median [range]: 20\% [16-44\%]) (Table 1, Online Supplementary Table S1). A unique chimerism profile was observed, with higher levels of donor chimerism in the $\mathrm{CD}^{+}$cells than in the other lineages unlike most of the included patients (Online Supplementary Figure S3-4).

This subgroup of patients was characterized by younger age at transplant (median [range]: 7.15 years [3.4-10.8]), a longer post-HSCT follow-up period (median [range]: 68.5 months [33-153]), and lower Hb levels (median [range]: $10.1 \mathrm{~g} / \mathrm{dL}$ [8.4-11.8]), when compared with the other patients in group 1. As mentioned above, HbS levels in these patients were higher than the corresponding donors (Figure 2, Online Supplementary Table S1). For these six patients, the reticulocyte count at last follow-up was greater than $100 \times 10^{9} / \mathrm{L}$; however, this was associated with a $\mathrm{Hb}$ level $<10 \mathrm{~g} / \mathrm{dL}$ only in three with very low myeloid chimerism $(\leq 21 \%)$ and transplanted with AS donors (patients \#2, \#8 and \#9, Online Supplementary Table S1). In these three cases, reticulocyte count was higher than $150 \times 10^{9} / \mathrm{L}$ and associated with an $\mathrm{HbS}>47.5 \%$. The three patients transplanted with an AS donor (patients \#2, \#8 and \#9) presented a particularly low level of donor myeloid chimerism $(5.4 \%, 10 \%$ and $16 \%$, respectivelythe lowest levels in the whole cohort) and highest $\mathrm{HbS}$ levels $(68.1 \%, 60.6 \%$ and $47.5 \%$, respectively) (Online
Supplementary Table S1). The three patients received donor lymphocyte infusions (DLI); this treatment did not modify the donor chimerism and was not associated with graft-versus-host disease (GvHD) occurrence. Two of the patients (\#2 and \#9) required sporadic RBC transfusions between 24 and 43 months after HSCT. Neither of them has required $\mathrm{RBC}$ transfusions since then. The three patients developed hemolytic anemia (patients \#2, \#8 and \#9), but only one had a suspected VOC with liver involvement (patient \#2; hepatic sequestration was confirmed by a histological assessment). Before HSCT, patient \#8 had presented with severe, SCD-related cerebral vasculopathy (bilateral stenosis of the cervical carotid arteries, and aneurism of the internal carotid arteries); this condition was stable after HSCT. Patients \#8 and \#9 are dizygotic twins who received grafts from different sibling AS donors ( $\mathrm{HbS}$ fractions in the donors: $44.6 \%$ and $43.6 \%$, respectively) at 5 years of age in 2003 and at 4 years of age in 2002, respectively. The level of donor chimerism fell rapidly in both twins, and then stabilized at a value below $20 \%$ in the second year post-HSCT. The HbS fraction progressively rose to a value of $60.6 \%$ and $47.5 \%$ in patients \#8 and \#9, respectively.

Interestingly, one patient (\#6, with an AA donor) displayed a WBC donor chimerism level as low as 19\% and myeloid chimerism of $31 \%$ but had a total $\mathrm{Hb}$ level of 11.8 $\mathrm{g} / \mathrm{dL}$ and an $\mathrm{HbS}$ percentage of $5.6 \%$.

Our results showed that $\mathrm{HbS}$ levels were closely correlated with chimerism in the myeloid compartment. The analyses of a subgroup of patients with low donor chimerism suggested that a myeloid chimerism of $30 \%$ is sufficient for preventing VOC in transplants from AA donors but not constantly from AS donors; in contrast, the 


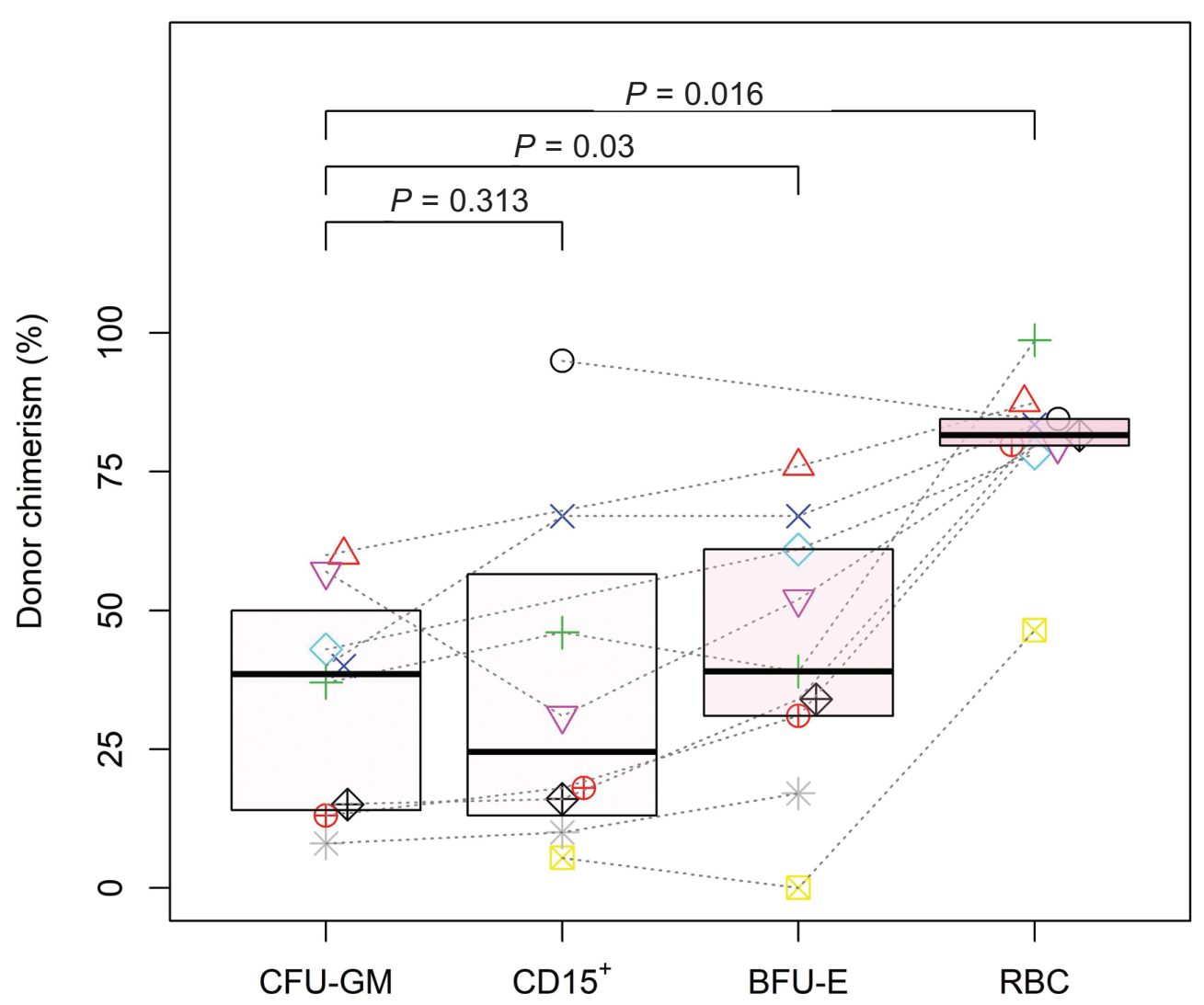

Figure 3. Donor chimerism (\%) in peripheral red blood cells (RBC), erythroid burst forming units (BFU-E), CD15+ cells and granulocyte-macrophage colony-formingunits (CFU-GM) progenitors/precursors in patients with donor chimerism $<70 \%$ (group 1), independently of the donor's genotype. Each patient is represented by a different symbol.

full correction of hemolytic anemia requires a higher level of myeloid donor chimerism (i.e. $>50 \%$ ) - particularly in patients with an AS donor.

\section{Discussion}

After HSCT, the majority of our patients with SCD will develop mixed chimerism (as defined in the Methods section). This condition is associated with a sufficient level of disease control, and represents an ideal setting for investigating (i) the reconstitution of the hematopoietic lineages following HSCT, and (ii) the minimum level of correction required to prevent the recurrence of clinical signs of SCD.

Chimerism analysis of total WBC is frequently used to evaluate donor cell engraftment following HSCT. However, in the context of MC, this tool does not provide an exhaustive analysis of donor engraftment. The present study is the first to have featured detailed, simultaneous analyses of chimerism in several different mature myeloid and lymphoid subpopulations, erythroid and myeloid progenitors/precursors, and peripheral RBC in a large cohort of patients having undergone myeloablative conditioning.

When simultaneously analyzing the donor/recipient origin of different hematologic lineages, we observed a linear correlation between $\mathrm{CD} 15^{+} / \mathrm{CD} 14^{+}, \mathrm{CD} 15^{+} / \mathrm{CD} 19^{+}$and CD14 $/ \mathrm{CD} 9^{+}$cells; this was also observed in our gene therapy trials (unpublished data). Chimerism of $\mathrm{CD}^{+}$cells was not correlated with other cell populations. With the exception of the subgroup of patients with the lowest levels of recipient chimerism (including the three symptomatic patients), patients had a lower percentage of donor cells in the $\mathrm{CD}^{+}$population than in the other lineages. Hence, T-cell reconstitution appears to be independent of the other lineages. An alternative explanation to this observation is that a minimum level of T-cell chimerism may be necessary for any myeloid chimerism, and/or that particular T-cell subsets may be critical for myeloid engraftment. Data available at the moment cannot formally confirm this hypothesis, however to our knowledge no myeloid chimerism was observed with no T-cell engraftment. It is possible that especially for low levels of donor chimerism a T-cell population could be necessary to allow the engraftment of myeloid cells in the bone marrow.

This finding shows that whole blood chimerism analysis is not appropriate for evaluating engraftment - especially in patients with $\mathrm{MC}$, and provides an insight into the hematopoietic reconstitution after HSCT in these patients.

One of the present study's main objectives was to evaluate the minimum level of donor engraftment needed to prevent the recurrence of clinical signs of SCD. Most SCD-related morbidity is caused by altered RBC; hence, we focused on changes in donor chimerism during erythroid development. Nearly all the patients displayed full donor chimerism in peripheral RBC, despite variable degrees of $\mathrm{MC}$ in other cell populations; this suggests that donor RBC have a lineage-specific selective advantage in 
the recipient. In order to investigate this putative selective advantage over the course of erythroid development, we compared donor chimerism among compartments at different stages of development. Our results show that not only the peripheral donor RBC have a selective advantage related to the shortened lifetime of SCD RBC but also the earlier erythroid progenitor/precursors. Despite the results of studies suggesting that the selective advantage is restricted to RBC in the periphery, ${ }^{23,28}$ our hypothesis has already been proposed in small series of patients. ${ }^{17,20}$ Indeed, the selective advantage of donor erythroid progenitor/precursors could be due to the ineffective erythropoiesis in SCD, as shown by the loss of SCD erythroblasts reported in patients with MC. ${ }^{24}$ Interestingly, in a SCD patient with $M C$, the expression of the apoptotic regulator Fas was significantly higher in recipient than in donor erythroblasts and RBC, ${ }^{29}$ suggesting that SCD "ineffective" erythroid cells undergo apoptosis, while donor cells have a survival advantage.

We further focused on a group of patients with low levels of donor chimerism ( $<70 \%$ for total WBC), and in particular on a subgroup of six patients who presented a donor chimerism level $\leq 50 \%$. Indeed, as reported in the overall French cohort, ${ }^{22}$ donor chimerism values as low as $16 \%, 18 \%$ and $21 \%$ for total WBC were recorded; these patients were the only ones to display high $(>45 \%) \mathrm{HbS}$ levels, hemolytic anemia and (in one case) a hepatic VOC. All three patients had an AS donor. These patients also presented the lowest level of donor chimerism in CD15 cells $(5.4 \%, 10 \%$ and $16 \%)$, which was more closely correlated than WBC chimerism with the HbS level.

In contrast, patients with total WBC chimerism $\leq 50 \%$ and AA donors had low HbS levels and no anemia, although high reticulocyte counts were recorded. In the study population as a whole, there were no significant differences between patients with an AA donor and those with an AS donor. However, when the level of donor chimerism was low, having an AA donor was an advantage.

Three patients with the lowest levels of donor myeloid chimerism received donor lymphocyte infusions during follow up in order to stabilize donor cells engraftment. Of note no modification in donor chimerism was observed after infusion. The use of donor lymphocyte infusion in this context is debated as the risks might exceed the benefits.

Although our results came from a small number of patients, they show that individuals with a myeloid donor chimerism level above $30 \%$ have stable, sufficient levels of total $\mathrm{Hb}$ and no longer display the clinical signs of SCD - regardless of the donor's Hb genotype. In contrast, the full correction of hemolytic anemia requires higher myeloid donor chimerism levels (i.e. $>50 \%$ ) - particularly for patients with an AS donor. A myeloid donor chimerism level as low as $30 \%$ was sufficient to prevent VOC in patients with AA donors but not constantly in those with AS donors. For patients with very low degree of myeloid donor engraftment, an AS graft is associated with a higher risk of SCD symptoms.

By defining the level of correction needed to obtain clinical remission in SCD, the present study provides important information for patients undergoing autologous transplantation of genetically modified hematopoietic stem cells (HSC). It is important to note that today's lentiviral-based gene addition strategies and genome-editing approaches aimed at reactivating the expression of the anti-sickling fetal $\gamma$-globin at best generate a heterozygous phenotype in vitro; therapeutic hemoglobin accounts for at most $60 \%$ of the total $\mathrm{Hb}$ types, e.g. in RBC derived from HSC harboring multiple copies of the vector. ${ }^{30}$ Under these optimal conditions (i.e. generation of AS-like HSC), our analyses of SCD patients with MC suggested that an HSC genetic modification rate below 30\% would not be sufficient to ameliorate the SCD clinical phenotype, whereas a myeloid donor chimerism level $\geq 30 \%$ would probably lead to clinical improvements. Furthermore, our present results suggest that in order to fully control hemolysis, this threshold should be raised to $>50 \%$. Under suboptimal conditions (i.e. therapeutic $\mathrm{Hb}$ $<60 \%$ ), we predict that a donor chimerism level largely exceeding $30 \%$ would be required to correct the SCD clinical phenotype.

Consistently, the initial clinical data from gene therapy trials highlighted the absence of clinical benefit in patients with SCD harboring 10-30\% of transduced HSC and low therapeutic $\mathrm{Hb}$ levels (i.e. 0.1-1.2 g/dL, which probably accounts for $<10 \%$ of the total Hb types [31]. In contrast, clinical remission was observed in a SS patient with a mean vector copy number per cell of $\sim 2,>60 \%$ of genetically modified HSC, and therapeutic $\mathrm{Hb}$ levels accounting for $\sim 50 \%$ of the total $\mathrm{Hb}^{1{ }^{14}}$

In conclusion, these findings show that the degree of myeloid donor engraftment (rather than T cells) is a better predictor of the disease control in these patients - as shown by the inverse correlation between $\mathrm{HbS}$ levels and the chimerism in the myeloid lineage. According to these observations the whole blood chimerism could be appropriate for evaluating engraftment when donor chimerism is higher than $50 \%$, but it looks unsatisfactory for patients developing lower donor chimerism; in this case a lineagespecific chimerism analysis should be preferred.

Our results provide a new insight into the selective advantage of donor erythroid cells in SCD patients. In particular, we show that not only donor peripheral RBC but also progenitors/precursors have a selective advantage over the recipient cells. Lastly, our study provides important clues for future gene therapy trials, and suggests that higher levels of gene correction will be needed to obtain full disease control.

\section{Acknowledgments}

The authors would like to thank patients and their families.

\section{Funding}

This work was funded by grants from "Cordons de Vie" charity and Agence Nationale de la Recherche (ANR-10-IAHU-01 "Investissements d'Avenir" program). This project has received funding from the European Union's Horizon 2020 research and innovation program under grant agreement No 693762 - Gene For Cure. 


\section{References}

1. Kato GJ, Piel FB, Reid CD, et al. Sickle cell disease. Nat Rev Dis Prim. 2018;4:18010.

2. Williams TN, Weatherall DJ. World distribution, population genetics, and health burden of the hemoglobinopathies. Cold Spring Harb Perspect Med. 2012; 2(9):a011692.

3. Piel FB, Patil AP, Howes RE, et al. Global epidemiology of sickle haemoglobin in neonates: a contemporary geostatistical model-based map and population estimates. Lancet. 2013;381(9861):142-151.

4. Bernaudin F, Socie G, Kuentz M, et al. Longterm results of related myeloablative stemcell transplantation to cure sickle cell disease. Blood. 2007;110(7):2749-2756.

5. Bhatia M, Walters MC. Hematopoietic cell transplantation for thalassemia and sickle cell disease: past, present and future. Bone Marrow Transplant. 2008;4(2):109-117.

6. Gluckman E, Cappelli B, Bernaudin F, et al. Sickle cell disease: an international survey of results of HLA-identical sibling hematopoietic stem cell transplantation. Blood. 2017;129(11):1548-1556.

7. Bernaudin F, Kuentz M. Haplo-BMT: cure or back to sickle cell? Blood. 2012;120(22): 4276-4277.

8. Gaziev J, Isgrò A, Sodani $\mathrm{P}$, et al. Haploidentical HSCT for hemoglobinopathies: improved outcomes with TCR +/CD19+-depleted grafts. Blood Adv. 2018;2(3):263-270

9. Krishnamurti L, Neuberg DS, Sullivan KM, et al. Bone marrow transplantation for adolescents and young adults with sickle cell disease: Results of a prospective multicenter pilot study. Am J Hematol. 2019; 94(4):446454.

10. Hsieh MM, Fitzhugh CD, Weitzel RP, et al. Nonmyeloablative HLA-matched sibling allogeneic hematopoietic stem cell transplantation for severe sickle cell phenotype. JAMA 2014;312(1):48-56.

11. King AA, Kamani N, Bunin N, et al. Successful matched sibling donor marrow transplantation following reduced intensity conditioning in children with hemoglobinopathies. Am J Hematol. 2015; 90(12):
1093-1098

12. Bhatia M, Jin Z, Baker C, et al. Reduced toxicity, myeloablative conditioning with $\mathrm{BU}$, fludarabine, alemtuzumab and SCT from sibling donors in children with sickle cell disease. Bone Marrow Transplant. 2014;49(7): 913-920.

13. Bolaños-Meade J, Fuchs EJ, Luznik L, et al. HLA-haploidentical bone marrow transplantation with posttransplant cyclophosphamide expands the donor pool for patients with sickle cell disease. Blood. 2012;120(22):4285-4291.

14. Ribeil J-A, Hacein-Bey-Abina S, Payen E, et al. Gene therapy in a patient with sickle cell disease. N Engl J Med. 2017;376(9):848 855.

15. Cavazzana M, Antoniani C, Miccio A. Gene therapy for $\beta$-hemoglobinopathies. Mol Ther. 2017;25(5):1142-1154

16. Andreani M, Testi M, Lucarelli G. Mixed chimerism in haemoglobinopathies: from risk of graft rejection to immune tolerance. Tissue Antigens. 2014;83(3):137-146.

17. Wu CJ, Gladwin M, Tisdale J, et al. Mixed haematopoietic chimerism for sickle cell disease prevents intravascular haemolysis. $\mathrm{Br} \mathrm{J}$ Haematol. 2007;139(3):504-507.

18. Andreani M, Testi M, Battarra M, et al. Split chimerism between nucleated and red blood cells after bone marrow transplantation for haemoglobinopathies. Chimerism. 2011;2 (1):21-22

19. Andreani M, Testi M, Gaziev J, et al. Quantitatively different red cell/nucleated cell chimerism in patients with long-term, persistent hematopoietic mixed chimerism after bone marrow transplantation for thalassemia major or sickle cell disease. Haematologica. 2011;96(1):128-133.

20. Walters MC, Patience M, Leisenring W, et al, Stable mixed hematopoietic chimerism after bone marrow transplantation for sickle cell anemia. Biol Blood Marrow Transplant. 2001;7(12):665-673

21. Abraham A, Hsieh M, Eapen $M$, et al. Relationship between mixed donor-recipient chimerism and disease recurrence after hematopoietic cell transplantation for sickle cell disease. Biol Blood Marrow Transplant. 2017;23(12):2178-2183

22. Bernaudin F, Dalle JH, Bories D, et al. Long- term event-free survival, chimerism and fertility outcomes in 234 patients with sicklecell anemia younger than 30 years after myeloablative conditioning and matchedsibling transplantation in France. Haematologica. 2019 May 16. [Epub ahead of print]

23. Fitzhugh CD, Cordes S, Taylor T, et al. At least $20 \%$ donor myeloid chimerism is necessary to reverse the sickle phenotype after allogeneic HSCT. Blood. 2017;130(17):19461948.

24. Wu CJ, Krishnamurti L, Kutok JL, et al Evidence for ineffective erythropoiesis in severe sickle cell disease. Blood. 2005;106(10):3639-3645

25. Miccio A, Cesari R, Lotti F, et al. In vivo selection of genetically modified erythroblastic progenitors leads to long-term correction of beta-thalassemia. Proc Natl Acad Sci U S A. 2008;105(30):10547-10552

26. Andreani M, Manna M, Lucarelli G, et al. Persistence of mixed chimerism in patients transplanted for the treatment of thalassemia. Blood. 1996:87(8):3494-3499.

27. Alizadeh M, Bernard M, Danic B, et al. Quantitative assessment of hematopoietic chimerism after bone marrow transplantation by real-time quantitative polymerase chain reaction. Blood. 2002;99(12):46184625 .

28. Altrock PM, Brendel C, Renella R, et al Mathematical modeling of erythrocyte chimerism informs genetic intervention strategies for sickle cell disease. Am J Hematol. 2016;91(9):931-937.

29. Marziali M, Isgrò A, Sodani $\mathrm{P}$, et al Peripheral red blood cell split chimerism as a consequence of intramedullary selective apoptosis of recipient red blood cells in a case of sickle cell disease. Mediterr J Hematol Infect Dis. 2014;6(1):e2014066.

30. Weber L, Poletti V, Magrin E, et al. An optimized lentiviral vector efficiently corrects the human sickle cell disease phenotype. Mol Ther Methods Clin Dev. 2018;10:268280

31. Kanter J, Tisdale J, Kwiatkowski J et al Outcomes for initial patient cohorts with up to 33 months of follow-up in the Hgb-206 phase 1 trial. Blood. 2018;132(Suppl 1):1080 